\title{
Posterior convex release and interbody fusion for thoracic scoliosis: technical note
}

\author{
Jean-Marc Mac-Thiong, MD, PhD, ${ }^{1-3}$ Jahangir Asghar, MD, ${ }^{4}$ Stefan Parent, MD, PhD, ${ }^{1-3}$ \\ Harry L. Shufflebarger, MD, ${ }^{4}$ Amer Samdani, MD, ${ }^{5}$ and Hubert Labelle, MD ${ }^{1,2}$ \\ 'Department of Surgery, University of Montreal; ${ }^{2}$ Department of Surgery, CHU Sainte-Justine; ${ }^{3}$ Department of Surgery, Hôpital \\ du Sacré-Coeur, Montreal, Quebec, Canada; ${ }^{4}$ Center for Spinal Disorders, Miami Children's Hospital, Miami, Florida; and \\ ${ }^{5}$ Department of Surgery, Shriner's Hospital, Philadelphia, Pennsylvania
}

\begin{abstract}
Anterior release and fusion is sometimes required in pediatric patients with thoracic scoliosis. Typically, a formal anterior approach is performed through open thoracotomy or video-assisted thoracoscopic surgery. The authors recently developed a technique for anterior release and fusion in thoracic scoliosis referred to as "posterior convex release and interbody fusion" (PCRIF). This technique is performed via the posterior-only approach typically used for posterior instrumentation and fusion and thus avoids a formal anterior approach. In this article the authors describe the technique and its use in 9 patients - to prevent a crankshaft phenomenon in 3 patients and to optimize the correction in 6 patients with a severe thoracic curve showing poor reducibility. After Ponte osteotomies at the levels requiring anterior release and fusion, intervertebral discs are approached from the convex side of the scoliosis. The annulus on the convex side of the scoliosis is incised from the lateral border of the pedicle to the lateral annulus while visualizing and protecting the pleura and spinal cord. The annulus in contact with the pleura and the anterior longitudinal ligament are removed before completing the discectomies and preparing the endplates. The PCRIF was performed at 3 levels in 4 patients and at 4 levels in 5 patients. Mean correction of the main thoracic curve, blood loss, and length of stay were $74.9 \%, 1290 \mathrm{ml}$, and 7.6 days, respectively. No neurological deficit, implant failure, or pseudarthrosis was observed at the last follow-up. Two patients had pleural effusion postoperatively, with 1 of them requiring placement of a chest tube. One patient had pulmonary edema secondary to fluid overload, while another patient underwent reoperation for a deep wound infection 3 weeks after the initial surgery.

The technique is primarily indicated in skeletally immature patients with open triradiate cartilage and/or severe scoliosis. It can be particularly useful if there is significant vertebral rotation because access to the disc and anterior longitudinal ligament from the convex side will become safer. The PCRIF is an alternative to the formal anterior approach and does not require repositioning between the anterior and posterior stages, which prolongs the surgery and can be associated with an increased complication rate. The procedure can be done in the presence of preexisting pulmonary morbidity such as pleural adhesions and decreased pulmonary function because it does not require mobilization of the lung or single-lung ventilation. However, PCRIF can still be associated with pulmonary complications such as a pleural effusion, and care should be taken to avoid iatrogenic injury to the pleura. Placement of a deep wound drain at the level of the PCRIF is strongly recommended if postoperative bleeding is anticipated, to decrease the risk of pleural effusion. http://thejns.org/doi/abs/10.3171/2016.2.SPINE15557
\end{abstract}

KEY WORDS anterior release; discectomy; interbody fusion; posterior approach; scoliosis; spine; surgery; technique; deformity

$\mathrm{A}$ NTERIOR release and fusion is still sometimes required in pediatric patients with thoracic scoliosis. ${ }^{1}$ It is most often performed in skeletally immature patients (Risser Stage 0 with open triradiate cartilage) to prevent a crankshaft phenomenon, in patients with severe deformities to improve curve correction, or in patients who are at increased risk for pseudarthrosis. ${ }^{1,7}$, With regard to the crankshaft phenomenon, Sponseller et al. ${ }^{13}$ have observed that in patients with open triradiate cartilage, the curve progression is significantly greater with posterior-

ABBREVIATIONS ALL = anterior longitudinal ligament; MEP = motor evoked potential; PCRIF = posterior convex release and interbody fusion; VATS = video-assisted thoracoscopic surgery. 
only spinal fusion using pedicle screws alone than with anteroposterior fusion.

Currently, the 2 most common techniques used to obtain anterior release and interbody fusion in scoliosis are open thoracotomy or video-assisted thoracoscopic surgery (VATS). ${ }^{17}$ Open thoracotomy provides wide access for the resection of discs and anterior longitudinal ligament (ALL) for interbody fusion and allows improved correction of thoracic hypokyphosis. However, it is associated with potential morbidity related to the chest wall violation, such as pulmonary complications (atelectasis, pneumothorax, pleural effusion, hemothorax, and so forth) and intercostal neuralgia. ${ }^{18}$ Compared with open thoracotomy, VATS can decrease morbidity and pain, enhance cosmesis, and shorten recovery. ${ }^{14}$ Unfortunately, the superiority of VATS over open thoracotomy is still debated-especially when anterior instrumentation is used-mainly because of the steep learning curve and technical complexity related to VATS. ${ }^{12}$ A rigid scoliosis, a spinal deformity that is too close to the rib cage, or the presence of intrathoracic pleural adhesions can also be difficult to approach via VATS. ${ }^{9}$ Pulmonary function can be limiting in both open thoracotomy and VATS. ${ }^{9}$ A report from the Scoliosis Research Society suggests that when anterior and posterior approaches are combined, the complication rate is increased compared with the rate following anterior-only or posterior-only surgeries. ${ }^{1}$ In addition, combined procedures generally necessitate repositioning and re-draping between the anterior and posterior stages, although VATS with the patient prone can also be performed for anterior release and fusion. ${ }^{16}$

We recently developed a technique for anterior release and fusion for thoracic scoliosis referred to as "posterior convex release and interbody fusion" (PCRIF). This technique is performed via the posterior approach typically used for posterior instrumentation and fusion and thus avoids a formal anterior approach with VATS or open thoracotomy. Here we describe PCRIF and report on 9 pediatric patients who underwent the technique for thoracic scoliosis.

\section{Methods}

Institutional review boards at the 3 institutions where the procedure has been performed approved this retrospective study in all patients who had undergone PCRIF along with posterior instrumentation and fusion. All patients (or the parent if a patient was younger than 14 years old) were informed about the use of the PCRIF technique.

Structural Cobb angles, thoracic kyphosis, and sagittal and coronal balance were assessed preoperatively and at the latest postoperative follow-up. Maximal correction on preoperative side-bending films was also assessed. Sagittal balance was measured from the horizontal distance between the C-7 plumb line and the posterosuperior corner of the S-1 vertebral body (positive when the C-7 plumb line was in front), while coronal balance was measured from the horizontal distance between the C-7 plumb line and the central sacral vertical line (positive when the C-7 plumb line was to the right). All perioperative morbidity and complications, as well as blood loss and operative times, had been prospectively collected.

\section{The PCRIF Technique}

After inducing general anesthesia and performing single-lumen endotracheal intubation, somatosensory evoked potential and transcranial motor evoked potential (MEP) monitoring of the spinal cord is initiated. The patient is positioned prone and is prepared and draped as for usual posterior instrumentation and fusion for scoliosis. The spine is exposed subperiosteally until the transverse processes are reached through a midline posterior incision over the appropriate fusion levels. All anchors (screws and hooks) are placed except on the convex side at the levels to be released and fused anteriorly. At these specific levels on the convex side, pilot holes for pedicle screws are prepared, tapped, and filled with bone wax for hemostasis without inserting the pedicle screws to facilitate the anterior release and fusion through the PCRIF technique. Alternatively, the anterior release and fusion through the PCRIF technique can be performed before implanting all anchors.

Ponte osteotomies are performed at the levels requiring anterior release and interbody fusion. Nerve roots are protected and preserved at all times. Appropriate intervertebral discs are approached only from the convex side of the scoliosis (Fig. 1). The lateral annulus on the convex side is then exposed until reaching the ALL while protecting the pleura. In some cases with severe rotational de-
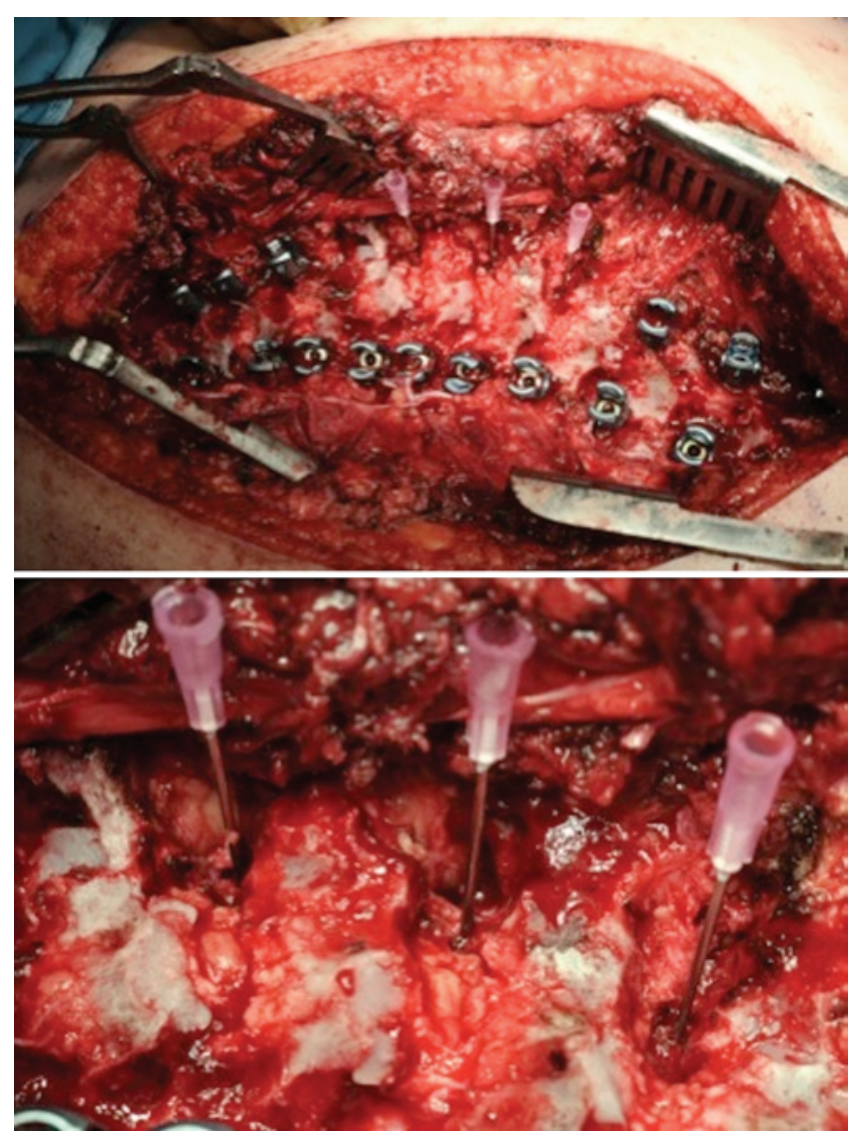

FIG. 1. Upper: Identification of appropriate intervertebral discs for PCRIF with 18-gauge needles. Lower: Magnified view of the identified disc spaces. Figure is available in color online only. 
formity and significant drooping of the ribs, access to the lateral border of the annulus and the ALL can be difficult. Consequently, the transverse process infra-adjacent to the disc and associated rib head (on 2-3 cm) was removed in all patients to safely perform the PCRIF. At this stage, an additional wider thoracoplasty can also be performed if desired. Given rotation of the spine at the peri-apical region, the disc will be shifted laterally on the convex side of the scoliosis. Therefore, the lateral border of the pedicle can be initially used as a landmark for the medial extent of the incision for the discectomy. The annulus on the convex side of the scoliotic curve is incised from the lateral border of the pedicle to the lateral annulus while visualizing and protecting the pleura and spinal cord. The annulus in contact with the pleura and the ALL are removed before completing the discectomies and preparing the endplates (Fig. 2 left). Reverse curettes and pituitary rongeurs are used to remove disc material toward the concave side. At this point, if desired, the annulus can be removed medially until the lateral border of the spinal cord is reached.

Bone graft can then be placed in the exposed interspaces if desired (Fig. 2 right), as was done for patients in Cases 1-5. Alternatively, bone on bone interbody fusion without interposed bone grafting can be performed, as was done in the patients in Cases 6-9. For 3 patients, a mixture of local bone obtained from the Ponte osteotomies and tricalcium phosphate granules (Conduit, DePuy) was used. For 2 other patients, we used local bone in addition to collagen fibers and hydroxyapatite sponges (Healos, DePuy) saturated with bone marrow aspirate to allow compression on the convex side. When placing interbody bone graft, care is taken not to overstuff the interspace on the convex side and interfere with curve correction. Remaining pedicle screws for which pilot holes have been prepared (or all pedicle screws if none are inserted yet) are then placed. The remaining steps for posterior instrumentation and fusion are then resumed. Except for the patient in Case 1, a deep wound drain was placed on the convex side up to the levels of the discectomies to decrease the risk of postoperative hemothorax. There is no need for a chest tube unless iatrogenic injury to the pleura occurs.
TABLE 1. Characteristics of patients who underwent PCRIF

\begin{tabular}{|c|c|c|c|c|c|}
\hline $\begin{array}{l}\text { Case } \\
\text { No. }\end{array}$ & Sex & $\begin{array}{l}\text { Age at } \\
\text { Op (yrs) }\end{array}$ & $\begin{array}{l}\text { Risser } \\
\text { Stage }\end{array}$ & Diagnosis & $\begin{array}{c}\mathrm{FU} \\
\text { (mos) }\end{array}$ \\
\hline 1 & $\mathrm{~F}$ & 11.2 & 0, OTC & Juvenile idiopathic scoliosis & 39 \\
\hline 2 & $\mathrm{~F}$ & 9.8 & 0, OTC & Juvenile idiopathic scoliosis & 51 \\
\hline 3 & $\mathrm{~F}$ & 11.3 & 0, OTC & Juvenile idiopathic scoliosis & 34 \\
\hline 4 & $\mathrm{~F}$ & 11.9 & 0 & $\begin{array}{l}\text { Adolescent idiopathic sco- } \\
\text { liosis \& Down syndrome }\end{array}$ & 52 \\
\hline 5 & M & 17.9 & 4 & $\begin{array}{l}\text { Adolescent idiopathic } \\
\text { scoliosis }\end{array}$ & 27 \\
\hline 6 & $\mathrm{~F}$ & 12.3 & 4 & $\begin{array}{l}\text { Adolescent idiopathic } \\
\text { scoliosis }\end{array}$ & 26 \\
\hline 7 & $\mathrm{~F}$ & 11.9 & 2 & Juvenile idiopathic scoliosis & 24 \\
\hline 8 & $\mathrm{~F}$ & 14.2 & 4 & $\begin{array}{l}\text { Adolescent idiopathic } \\
\text { scoliosis }\end{array}$ & 27 \\
\hline 9 & $\mathrm{~F}$ & 15.9 & 4 & $\begin{array}{l}\text { Adolescent idiopathic } \\
\text { scoliosis }\end{array}$ & 23 \\
\hline
\end{tabular}

FU = follow-up; OTC = open triradiate cartilage.

\section{Results}

Intraoperative and radiographic characteristics of 9 pediatric patients who underwent PCRIF are presented in Tables 1-4. All patients had idiopathic scoliosis with a major thoracic curve, although 1 patient had concomitant Down syndrome. For 3 patients (Cases 1-3), PCRIF was indicated to prevent a crankshaft phenomenon in a skeletally immature patient with Risser Stage 0 and open triradiate cartilage. We decided to perform PCRIF in the other 6 patients because of the severity of the main thoracic curve and poor reducibility on bending films. Contraindications to PCRIF included the presence of a neural axis abnormality and the need for anterior release above the T2-3 or below the T11-12 levels. The technique was performed at 3 consecutive levels in 4 patients and at 4 consecutive levels in 5 patients. Mean correction of the main thoracic curve at the latest follow-up was $74.9 \%$ (median $74.6 \%$, range $58.3 \%-83.6 \%$ ), whereas mean re-
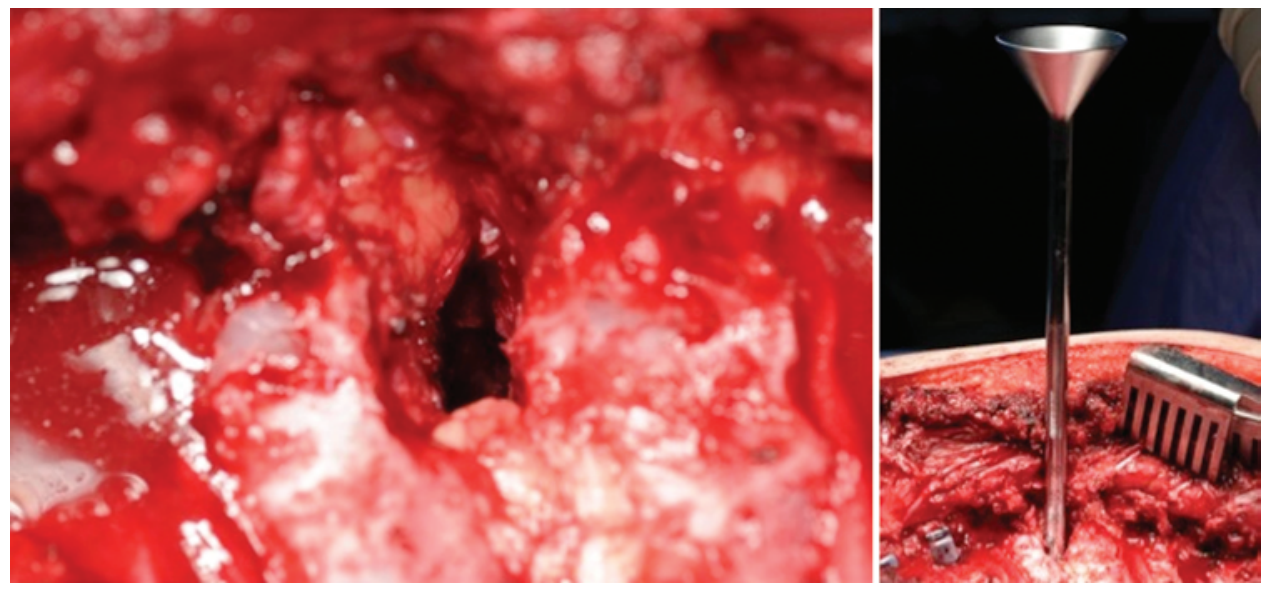

FIG. 2. Left: Completion of the discectomy. Right: Insertion of bone graft into the disc space. Figure is available in color online only. 
TABLE 2. Intraoperative characteristics and length of stay in patients who underwent PCRIF

\begin{tabular}{llllll}
\hline $\begin{array}{c}\text { Case } \\
\text { No. }\end{array}$ & \multicolumn{2}{c}{ Fused Levels } & $\begin{array}{c}\text { Op Time } \\
\text { (mins) }\end{array}$ & $\begin{array}{c}\text { Blood } \\
\text { Loss }(\mathrm{ml})\end{array}$ & $\begin{array}{c}\text { LOS } \\
\text { (days) }\end{array}$ \\
\hline 1 & T2-L1 & T6-10 & 390 & 950 & 10 \\
\hline 2 & T3-L1 & T6-9 & 360 & 710 & 7 \\
\hline 3 & T3-L3 & T7-10 & 405 & 1330 & 8 \\
\hline 4 & T3-L3 & T6-10 & 450 & 1075 & 8 \\
\hline 5 & T3-L3 & T8-11 & 365 & 3865 & 8 \\
\hline 6 & T2-L4 & T6-10 & 480 & 1263 & 6 \\
\hline 7 & T2-L3 & T6-10 & 440 & 895 & 7 \\
\hline 8 & T4-L3 & T7-10 & 470 & 770 & 8 \\
\hline 9 & T2-L4 & T6-10 & 495 & 760 & 6 \\
\hline
\end{tabular}

ducibility was $17.7 \%$ (median $18.6 \%$, range $6.3 \%-29.7 \%$ ). For the patients in Cases 1-3, who underwent PCRIF to prevent a crankshaft phenomenon, there was no evidence of progression or crankshaft phenomenon (defined as progression of the major Cobb angle by $10^{\circ}$ or more) during follow-up. Preoperative, bending, and postoperative radiographs for patients in Cases 1 and 4 are shown in Figs. 3 and 4, respectively. Radiographs in Fig. 5 show evidence of interbody fusion at the T6-9 levels 51 months after surgery in the patient in Case 2.

The mean blood loss and length of stay were $1290 \mathrm{ml}$ (median $950 \mathrm{ml}$, range $710-3865 \mathrm{ml}$ ) and 7.6 days (median 8 days, range $6-10$ days), respectively. The mean length of follow-up after surgery was 34 months (median 27 months, range 23-52 months).

Complications are described in Table 5. There were 3 pulmonary complications (33\%) in our series. One patient (11\%) had a loss of intraoperative MEPs, but her wake-up test and postoperative neurological examination demonstrated normal function. One patient (11\%) had excessive epidural venous bleeding during the PCRIF procedure. One patient (11\%) returned to the operating room for a deep wound infection. No neurological deficit was observed after surgery. Nor was any implant failure noted at the last follow-up.

\section{Discussion}

In this study we describe PCRIF for anterior release and fusion of the thoracic spine in scoliosis. Using this technique, we were able to achieve multilevel anterior release and interbody fusion in 9 patients with main thoracic scoliosis using direct visualization of the intervertebral discs via a posterior-only approach. Because PCRIF is performed through the same posterior approach used for posterior instrumentation and fusion, it avoids the formal anterior approach in VATS or open thoracotomy that is sometimes used in skeletally immature patients with open triradiate cartilage and/or for severe scoliosis.

Posterior convex release and interbody fusion is particularly useful when there is significant vertebral rotation at the levels where anterior release is required. As vertebral rotation increases, access to and removal of the disc and ALL from the convex side of the scoliosis becomes safer since the lateral portion of the disc is directed more posteriorly while the spinal cord remains deviated on the concave side of the scoliosis. For the 5 severe cases in this study with Cobb angles greater than $90^{\circ}$ with less than $30 \%$ curve reducibility, PCRIF was also an alternative to a vertebral column resection for which the exposure is markedly more extensive and the risk of major complications can be high. ${ }^{1}$ Indeed, PCRIF allows 3-column correction through concomitant Ponte osteotomies and aggressive discectomies that can provide excellent coronal, axial, and sagittal correction of the scoliosis.

There are multiple advantages in using PCRIF instead of a formal anterior approach. First, PCRIF can be done in the presence of preexisting pulmonary morbidity such as pleural adhesions and decreased pulmonary function because it does not require mobilization of the lung or single-lung ventilation. Therefore, pulmonary function is not likely to be altered postoperatively. However, PCRIF can still be associated with pulmonary complications such as hemothorax, as was observed in 2 of our patients. Care should be taken to avoid iatrogenic injury to the pleura and the need for a chest tube. A postoperative chest radiograph can be ordered to rule out pneumothorax or hemothorax that was not noticed during surgery. Placement of a deep wound drain on the convex side at the level of the PCRIF is strongly recommended if postoperative bleeding in the wound is anticipated, to decrease the risk of hemothorax

TABLE 3. Curve characteristics of patients who underwent PCRIF

\begin{tabular}{|c|c|c|c|c|c|}
\hline \multirow[b]{2}{*}{ Case No. } & \multicolumn{3}{|c|}{ Cobb Angles $\left({ }^{\circ}\right)$} & \multicolumn{2}{|c|}{ Main Thoracic Curve } \\
\hline & Preop & Bending & Postop & Reducibility (\%) & Correction (\%) \\
\hline 1 & PT34, MT63, L33 & PT29, MT59, L27 & PT19, MT16, L19 & 6.3 & 74.6 \\
\hline 2 & PT32, MT70, L60 & PT3, MT57, L49 & PT1, MT19, L23 & 18.6 & 72.9 \\
\hline 3 & PT32, MT62, L53 & PT30, MT45, L26 & PT13, MT11, L12 & 27.4 & 82.3 \\
\hline 4 & PT51, MT98, L53 & PT50, MT78, L41 & PT30, MT28, L14 & 20.4 & 71.4 \\
\hline 5 & PT50, MT72, L48 & PT50, MT66, L29 & PT34, MT30, L21 & 8.3 & 58.3 \\
\hline 6 & PT32, MT128, L65 & PT27, MT90, L42 & PT16, MT21, L14 & 29.7 & 83.6 \\
\hline 7 & PT45, MT91, L62 & PT37, MT75, L31 & PT27, MT24, L19 & 17.6 & 73.6 \\
\hline 8 & PT24, MT92, L51 & PT12, MT72, L24 & PT19, M17, L12 & 21.7 & 81.5 \\
\hline 9 & PT27, MT101, L49 & PT20, MT92, L28 & PT21, MT24, L18 & 8.9 & 76.2 \\
\hline
\end{tabular}

$\mathrm{L}=$ lumbar; $\mathrm{MT}=$ main thoracic; $\mathrm{PT}=$ proximal thoracic. 
TABLE 4. Radiological characteristics of patients who underwent PCRIF

\begin{tabular}{|c|c|c|c|c|c|c|c|c|}
\hline \multirow[b]{2}{*}{ Case No. } & \multicolumn{2}{|c|}{ Thoracic Kyphosis $\left({ }^{\circ}\right)$} & \multicolumn{2}{|c|}{ Lumbar Lordosis $\left({ }^{\circ}\right)$} & \multicolumn{2}{|c|}{ Sagittal Balance $(\mathrm{cm})$} & \multicolumn{2}{|c|}{ Coronal Balance $(\mathrm{cm})$} \\
\hline & Preop & Postop & Preop & Postop & Preop & Postop & Preop & Postop \\
\hline 1 & 49 & 32 & 51 & 34 & 0.8 & 0.3 & 0.8 & 0.5 \\
\hline 2 & 28 & 25 & 54 & 51 & -0.2 & 0.7 & 1.6 & -1.4 \\
\hline 3 & 18 & 25 & 46 & 43 & -0.4 & -0.8 & 2.1 & -0.3 \\
\hline 4 & 56 & 45 & 91 & 77 & 4.2 & 2.5 & 2.1 & -0.5 \\
\hline 5 & 4 & 17 & 44 & 52 & -0.1 & 1.3 & 1.2 & -0.7 \\
\hline 6 & 15 & 27 & 49 & 32 & 1.0 & 0.5 & 2.6 & -0.4 \\
\hline 7 & 21 & 20 & 57 & 44 & 0.7 & 0.7 & 1.4 & -0.2 \\
\hline 8 & 31 & 34 & 44 & 35 & -0.9 & 0.3 & 1.8 & 0.9 \\
\hline 9 & 18 & 25 & 51 & 38 & 0.2 & 0.7 & 2.1 & 0.3 \\
\hline
\end{tabular}

postoperatively. As for the patients in Cases 1 and 8, it is presumed that postoperative bleeding from posterior tissues followed the path of least resistance and transuded through the chest cavity in the absence of a deep wound drain, causing pleural effusion.

Posterior convex release and interbody fusion does not require changing the setup, repositioning, or re-draping between the anterior and posterior stages, all of which typically prolong the surgery. We estimated that about 20 minutes per level was necessary to complete the osteotomy, anterior release, and fusion related to the PCRIF technique. Conversely, previous studies have shown that the mean operative time for scoliosis surgery is increased by more than 3 hours for combined procedures as compared with posterior-only procedures., ${ }^{3,5}$ These characteristics of PCRIF are important because they can contrib- ute to decreased operative and anesthesia times, while it is known that prolonged surgeries can be associated with an increased rate of complications in scoliosis surgery. 5,8 Since PCRIF does not require a formal anterior approach, it may also prevent specific anterior approach-related complications such as intercostal neuralgia, poor cosmesis from additional incision(s), or incisional pain. However, a case-control study must be performed to confirm these potential benefits of the PCRIF technique.

It has been observed that combined procedures for scoliosis, as compared with isolated anterior or posterior procedures, increase the risk of neurological complication. ${ }^{1,4,11}$ In a report from the Scoliosis Research Society, ${ }^{6}$ the rate of spinal cord injury following surgery for adolescent idiopathic scoliosis was significantly increased with combined procedures $(1.12 \%)$, as compared with the rate

\section{TABLE 5. Complications in 9 patients who underwent PCRIF}

\begin{tabular}{|c|c|c|}
\hline $\begin{array}{l}\text { Case } \\
\text { No. }\end{array}$ & Complication & Description \\
\hline 1 & Pleural effusion & $\begin{array}{l}\text { On postop Day } 1 \text {, desaturation w/ tachycardia \& tachypnea occurred secondary to rt pleural effusion presumably due to } \\
\text { transudation of blood accumulating from posterior wound (no wound drain placed intraoperatively); percutaneous drain- } \\
\text { age revealed presence of hemothorax, \& chest tube placed }\end{array}$ \\
\hline 2 & $\begin{array}{l}\text { Transient loss of } \\
\text { MEP }\end{array}$ & $\begin{array}{l}\text { SSEPs normal throughout op; MEPs at rt lower extremity dropped significantly by } 71 \%-98 \% \text { during Ponte osteotomies; } \\
\text { MAP increased to } 100 \mathrm{~mm} \mathrm{Hg} \text {, and MEPs progressively returned to normal values; after installation of first rod on con- } \\
\text { cave side, complete loss of MEPs in both lower extremities; MAP again increased \& some correction released; MEPs in } \\
\text { It lower extremity returned to normal, while MEPs in rt lower extremity increased to } 62 \% \text { of baseline values; op resumed } \\
\text { after normal wake-up test w/o any further attempt to correct deformity; MEPs gradually increased to normal baseline } \\
\text { values, \& patient showed completely normal neurological function postoperatively }\end{array}$ \\
\hline 3 & - & \\
\hline 4 & Pulmonary edema & $\begin{array}{l}\text { On postop Day 2, patient had progressive dyspnea \& tachypnea due to presence of bilat pulmonary edema secondary to } \\
\text { fluid overload, successfully treated w/ intravenous furosemide }\end{array}$ \\
\hline 5 & $\begin{array}{l}\text { Increased epidural } \\
\text { bleeding }\end{array}$ & $\begin{array}{l}\text { Increased bleeding ( } 3865 \mathrm{ml} \text { ) occurred mainly during accomplishment of PCRIF because of difficulty in controlling the } \\
\text { bleeding from epidural vessels }\end{array}$ \\
\hline 6 & - & \\
\hline 7 & - & \\
\hline 8 & Pleural effusion & $\begin{array}{l}\text { On postop Day 1, moderate rt pleural effusion observed \& resolved after giving intravenous furosemide \& aggressive } \\
\text { respiratory therapy }\end{array}$ \\
\hline 9 & $\begin{array}{l}\text { Deep wound } \\
\text { infection }\end{array}$ & $\begin{array}{l}\text { Serosanguinous drainage from wound noted } 3 \text { wks after surgery; patient returned to operating room for single irrigation \& } \\
\text { debridement, followed by } 6 \text { wks of intravenous antibiotic treatment \& } 3 \text { mos of oral antibiotics; no recurrence of infection } \\
\text { at latest FU } 23 \text { mos after initial op }\end{array}$ \\
\hline
\end{tabular}

$-=$ none; $\mathrm{MAP}=$ mean arterial pressure $;$ SSEP $=$ somatosensory evoked potential. 


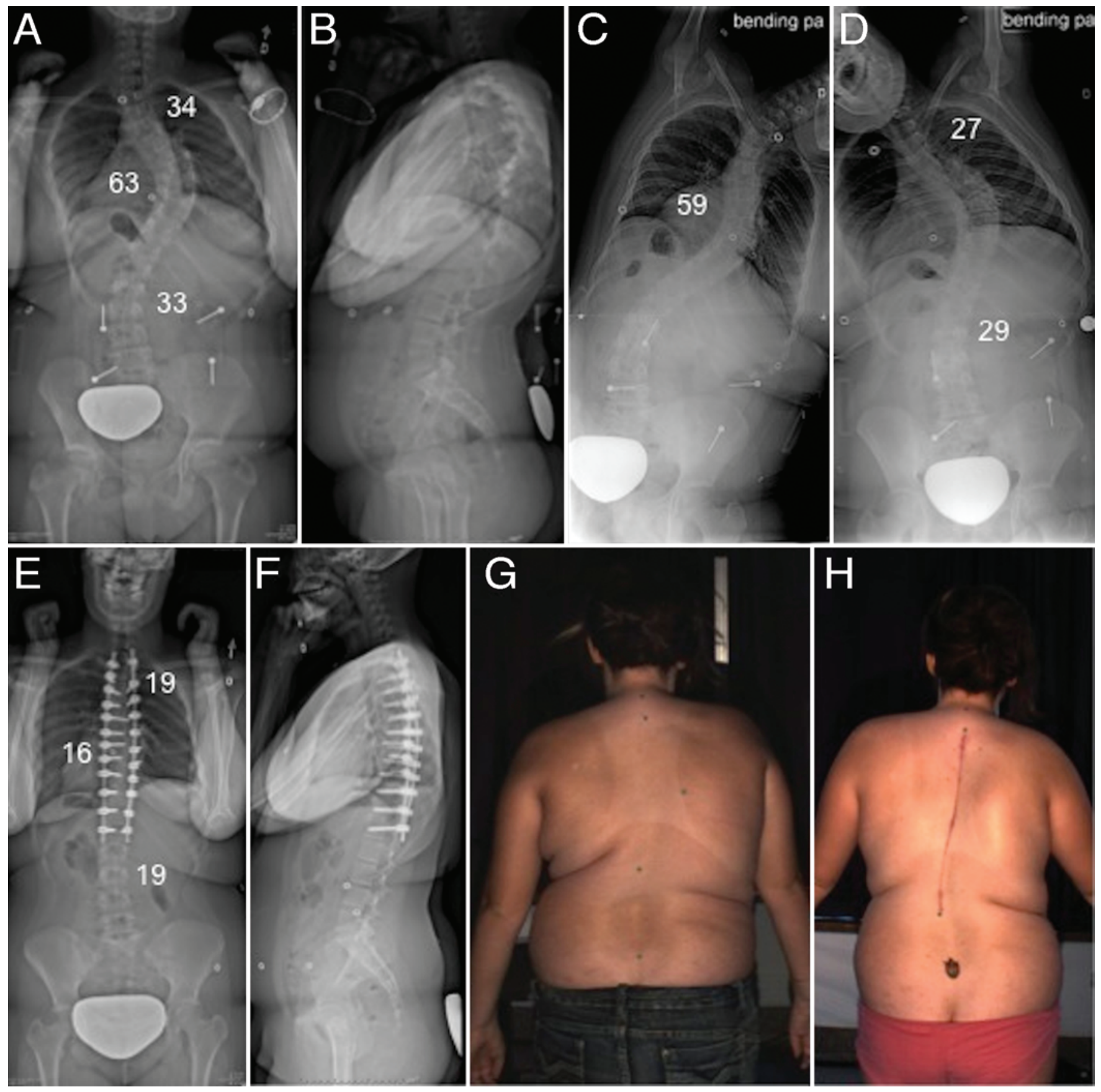

FIG. 3. Case 1. Preoperative (A and $\mathbf{B})$, side-bending ( $\mathbf{C}$ and $\mathbf{D}$ ), and last follow-up ( $\mathbf{E}$ and $\mathbf{F}$ ) radiographs obtained in a patient who underwent T2-L1 posterior instrumentation and fusion with PCRIF at T6-10. Preoperative (G) and postoperative (H) clinical photographs. Figure is available in color online only.

$(0.21 \%)$ following posterior-only procedures. In a recent review of 138 patients undergoing anterior thoracoscopic release and fusion, there were 2 incidents of paresthesia in the lower extremity. ${ }^{1}$ As for the patient in Case 2 in the current study, she also had one intraoperative neuromonitoring alert for which a wake-up test had to be performed and for which no postoperative deficit was observed. Similar to 3-column osteotomy techniques, the PCRIF technique can be associated with potential neurological injury given the need to work around the spinal cord when per- forming the discectomy and anterior fusion. Accordingly, a previous study of 240 patients undergoing 3-column osteotomy for spinal deformity found an overall neurological deficit rate of $5.6 \%$ for vertebral column resections. ${ }^{2}$ Two aspects related to the PCRIF technique could contribute to a decrease in the risk of neurological complication in combined procedures: 1) decrease in surgical time and 2) direct visualization and protection of the spinal cord during the anterior stage of the procedure. However, because the spinal cord is exposed after the Ponte osteotomies, the 


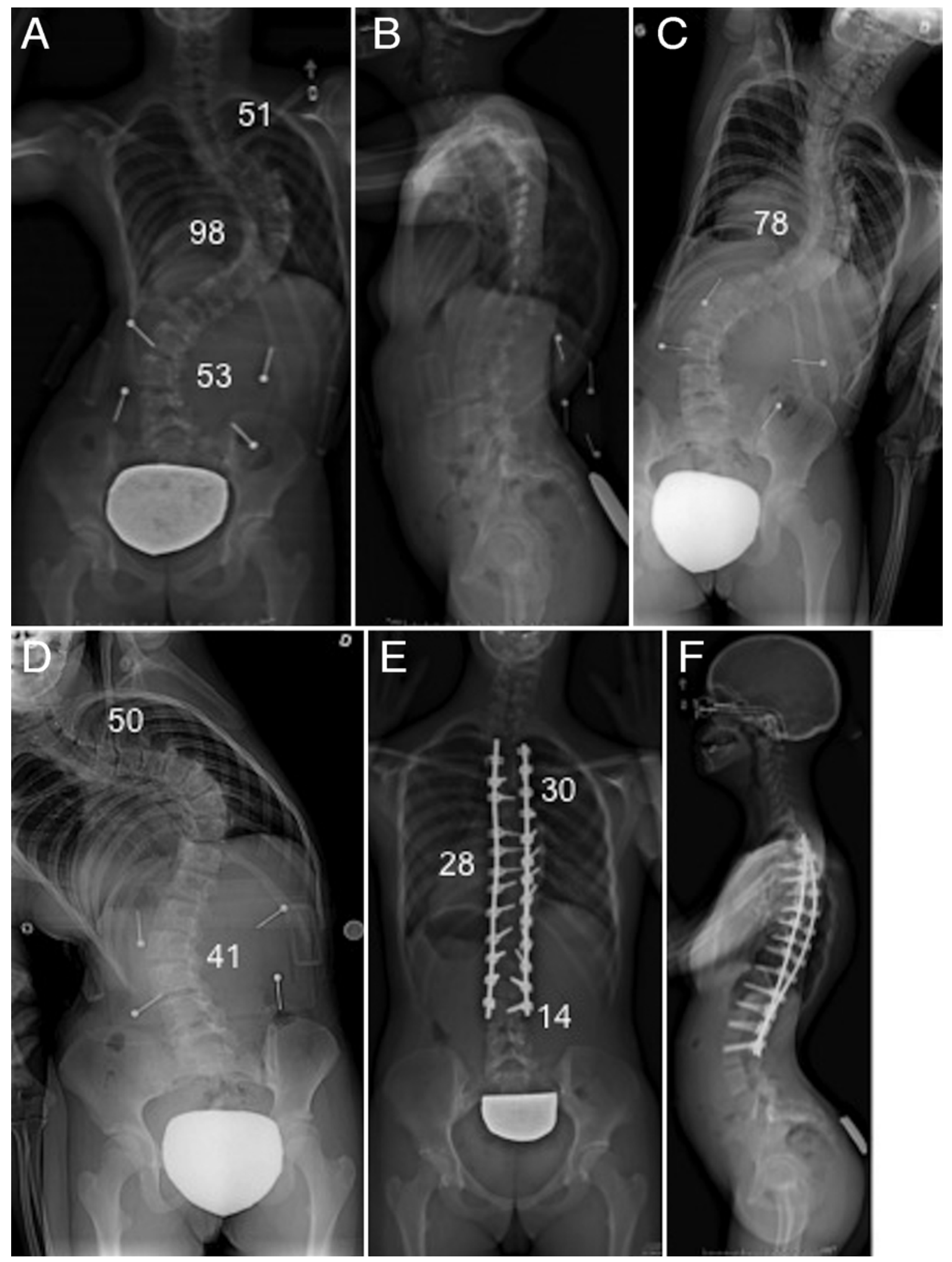

FIG. 4. Case 4. Preoperative (A-D) radiographs obtained in a patient showing severe adolescent idiopathic scoliosis with a main Cobb angle of $98^{\circ}$. Postoperative radiographs (E-F) obtained following T3-L3 posterior instrumentation and fusion via PCRIF at T6-10 resulting in a main Cobb angle of $28^{\circ}$ at the last follow-up.

PCRIF technique is associated with a risk of iatrogenic injury to the spinal cord, although no neurological deficit was observed in the current study.
Bleeding from the epidural vessels can also alter visualization of the discs and neurological structures, so that adequate hemostasis of epidural vessels is required when 

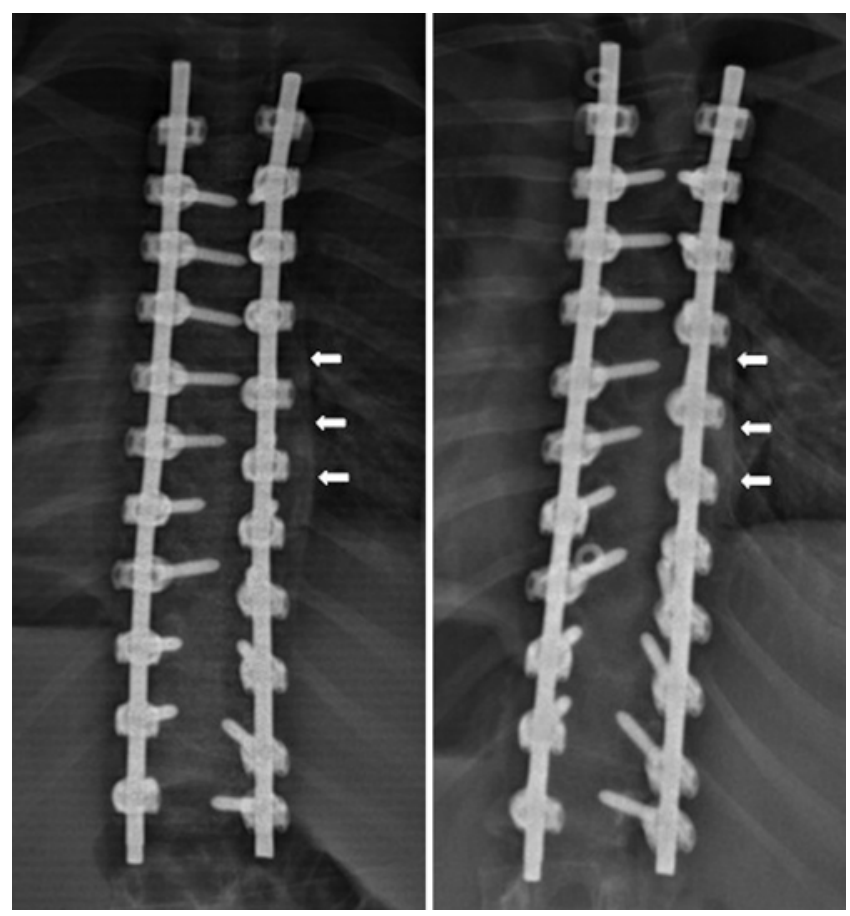

FIG. 5. Case 2. Left: Baseline postoperative radiograph obtained 1 week after surgery, showing T6-9 levels (arrows). Right: Follow-up radiograph obtained 51 months after surgery, showing evidence of interbody fusion at the T6-9 levels (arrows).

undertaking PCRIF. Exposing the discs and performing the discectomies are the most technically challenging parts of PCRIF and are undoubtedly associated with a learning curve.

As demonstrated by the 4 patients with preoperative thoracic kyphosis $<20^{\circ}$, the PCRIF technique can also potentially help to restore adequate thoracic kyphosis. This is in accordance with previous reports showing that an anterior approach usually increases thoracic kyphosis..$^{10,15}$ However, future studies are needed to determine if PCRIF is as effective as a formal anterior approach through thoracoscopy or open thoracotomy for not only restoring a normal sagittal profile but also improving curve correction and achieving anterior fusion.

\section{Conclusions}

In this study we described a new technique of PCRIF for thoracic scoliosis. The technique was performed at multiple peri-apical levels along with posterior instrumentation and fusion in 9 pediatric patients with thoracic scoliosis. This technique allows one to avoid a formal anterior approach via thoracoscopy or open thoracotomy, as well as mobilization of the lung. It can also be used as an alternative to a vertebral column resection for severe curves to achieve major correction in the coronal, axial, and sagittal planes. It is particularly useful when there is significant vertebral rotation because access to the disc and ALL from the convex side becomes safer. The effectiveness of PCRIF in achieving fusion, preventing the crankshaft phenomenon, improving quality of life, restoring a normal sagittal profile, and improving curve correction needs to be investigated in a future study involving a control group. As with other anterior procedures, PCRIF can be associated with potential risks that need to be thoroughly assessed in a larger study to better evaluate the risk/benefit ratio of the technique, as well as to define the best indication for this procedure.

\section{References}

1. Arunakul R, Peterson A, Bartley CE, Cidambi KR, Varley ES, Newton PO: The 15-year evolution of the thoracoscopic anterior release: does it still have a role? Asian Spine J 9:553-558, 2015

2. Auerbach JD, Lenke LG, Bridwell KH, Sehn JK, Milby $\mathrm{AH}$, Bumpass D, et al: Major complications and comparison between 3-column osteotomy techniques in 105 consecutive spinal deformity procedures. Spine (Phila Pa 1976) 15:1198-1210, 2012

3. Auerbach JD, Lonner BS, Antonacci MD, Kean KE: Perioperative outcomes and complications related to teaching residents and fellows in scoliosis surgery. Spine (Phila Pa 1976) 33:1113-1118, 2008

4. Bridwell KH, Lenke LG, Baldus C, Blanke K: Major intraoperative neurologic deficits in pediatric and adult spinal deformity patients. Incidence and etiology at one institution. Spine (Phila Pa 1976) 23:324-331, 1998

5. Carreon LY, Puno RM, Lenke LG, Richards BS, Sucato DJ, Emans JB, et al: Non-neurologic complications following surgery for adolescent idiopathic scoliosis. J Bone Joint Surg Am 89:2427-2432, 2007

6. Coe JD, Arlet V, Donaldson W, Berven S, Hanson DS, Mudiyam R, et al: Complications in spinal fusion for adolescent idiopathic scoliosis in the new millennium. A report of the Scoliosis Research Society Morbidity and Mortality Committee. Spine (Phila Pa 1976) 31:345-349, 2006

7. Davis MA: Posterior spinal fusion versus anterior/posterior spinal fusion for adolescent idiopathic scoliosis: a decision analysis. Spine (Phila Pa 1976) 34:2318-2323, 2009

8. Hod-Feins R, Abu-Kishk I, Eshel G, Barr Y, Anekstein Y, Mirovsky Y: Risk factors affecting the immediate postoperative course in pediatric scoliosis surgery. Spine (Phila Pa 1976) 32:2355-2360, 2007

9. Lonner BS, Auerbach JD, Estreicher MB, Betz RR, Crawford $\mathrm{AH}$, Lenke LG, et al: Pulmonary function changes after various anterior approaches in the treatment of adolescent idiopathic scoliosis. J Spinal Disord Tech 22:551-558, 2009

10. Newton PO, Yaszay B, Upasani VV, Pawelek JB, Bastrom TP, Lenke LG, et al: Preservation of thoracic kyphosis is critical to maintain lumbar lordosis in the surgical treatment of adolescent idiopathic scoliosis. Spine (Phila Pa 1976) 35:1365-1370, 2010

11. Qiu Y, Wang S, Wang B, Yu Y, Zhu F, Zhu Z: Incidence and risk factors of neurological deficits of surgical correction for scoliosis: analysis of 1373 cases at one Chinese institution. Spine (Phila Pa 1976) 33:519-526, 2008

12. Reddi V, Clarke DV Jr, Arlet V: Anterior thoracoscopic instrumentation in adolescent idiopathic scoliosis: a systematic review. Spine (Phila Pa 1976) 33:1986-1994, 2008

13. Sponseller PD, Jain A, Newton PO, Lonner BS, Shah SA, Shufflebarger H, et al: Posterior spinal fusion with pedicle screws in patients with idiopathic scoliosis and open triradiate cartilage: does deformity progression occur? J Pediatr Orthop [epub ahead of print], 2015

14. Sucato DJ: Thoracoscopic anterior instrumentation and fusion for idiopathic scoliosis. J Am Acad Orthop Surg 11:221-227, 2003

15. Sucato DJ, Agrawal S, O’Brien MF, Lowe TG, Richards SB, Lenke L: Restoration of thoracic kyphosis after operative 
treatment of adolescent idiopathic scoliosis: a multicenter comparison of three surgical approaches. Spine (Phila Pa 1976) 33:2630-2636, 2008

16. Sucato DJ, Elerson E: A comparison between the prone and lateral position for performing a thoracoscopic anterior release and fusion for pediatric spinal deformity. Spine (Phila Pa 1976) 28:2176-2180, 2003

17. Upasani VV, Newton PO: Anterior and thoracoscopic scoliosis surgery for idiopathic scoliosis. Orthop Clin North Am 38:531-540, vi, 2007

18. Weis JC, Betz RR, Clements DH III, Balsara RK: Prevalence of perioperative complications after anterior spinal fusion for patients with idiopathic scoliosis. J Spinal Disord 10:371375,1997

\section{Disclosures}

Dr. Samdani is a consultant for DePuy Synthes Spine, Globus
Medical, Zimmer, and Stryker. Dr. Shufflebarger is consultant for and receives royalties from DePuy Synthes Spine and K2M. Drs. Labelle, Parent, and Mac-Thiong own Spinologics Inc.

\section{Author Contributions}

Conception and design: all authors. Acquisition of data: Mac-

Thiong, Asghar. Analysis and interpretation of data: Mac-Thiong, Asghar, Parent, Labelle. Drafting the article: Mac-Thiong, Asghar. Critically revising the article: all authors. Reviewed submitted version of manuscript: all authors. Approved the final version of the manuscript on behalf of all authors: Mac-Thiong. Administrative/technical/material support: Mac-Thiong. Study supervision: Mac-Thiong, Labelle.

\section{Correspondence}

Jean-Marc Mac-Thiong, CHU Sainte-Justine, Department of Surgery, 3175 Cote-Sainte-Catherine, Montreal, QC H3T 1C5, Canada.email: macthiong@gmail.com. 